\title{
THE EXPERIENCES OF WOMEN IN UNDERGRADUATE ENGINEERING
}

\author{
Natalie Mazur ${ }^{1}$, Bronwyn Chorlton ${ }^{2}$, John Gales ${ }^{3 *}$ \\ ${ }^{1}$ University of Toronto \\ ${ }^{2}$ York University \\ ${ }^{3}$ York University \\ *jgales@yorku.ca
}

\begin{abstract}
While it is understood that there is an issue in retention of women in STEM fields, there is little research addressing why this is occurring. This warrants the need to begin identifying the root of this issue, and the direct causes. Undergraduate engineering programs are the first phase students undertake in their pursuit of a career as a professional engineer, and even in this early phase an issue in retention is apparent. The present study addresses factors that may be preventing female students from remaining in the field. In this study, 261 undergraduate students enrolled in engineering programs at an accredited university in Ontario completed a 17question survey that collected demographic data and asked questions related to challenges students may experience during their education. The survey questions were formulated to understand the severity to which each challenge affects males and females in different ways. Demographic factors were correlated with students' answers, and significant differences between men's and women's answers were found. $65 \%$ of female students reported more discouragement or intimidation by peers and professors in their program, compared to $45 \%$ of male students. These findings may indicate that female students may be more susceptible to a culture of intimidation than male students. Another significant finding lies within a survey question formulated to understand if female and male engineers have their contributions represented equally. This question showed that male students recognized the names of male engineers 1.75 times more often than they recognized the names of female engineers. The results of this question show that, to some capacity, male engineering students do not recognize female engineers' contributions as frequently as male engineers' contributions. Moving forward, there is a need to support female students in engineering as well as to educate students on respect and equity.
\end{abstract}

Keywords: diversity, STEM, WSTEM, women, gender, undergraduate, education

CEEA18; Paper 35

University of British Columbia; June 3-6, 2018- 1 of $10-$

\section{INTRODUCTION}

Female undergraduate enrolment in engineering programs has been stagnant at under 30 percent in Canada for the past twenty years $[5,11]$. The reasons behind this trend are not differing gender abilities in the relevant subjects. Male and female students perform equally well on subjects important to engineering programs, such as mathematics $[5,15,19]$. There is no one gender that is cognitively or intellectually superior in any subject. The only significant factor in students' interest in pursuing engineering and other STEM (Science, Technology, Engineering, and Mathematics) fields is self-perception $[15,17,22,25]$. Females who decide to pursue STEM fields have a more positive perception of their math abilities, but do not necessarily have better scores than their female peers who pursue non-STEM subjects in post-secondary education $[10,19]$. It is clear that females have an equal chance for success in engineering careers as males do. However, the low recruitment rate of females in undergraduate engineering programs suggests that females are still deterred from pursuing an undergraduate engineering degree.

The alienation of women from undergraduate programs begins earlier than university recruitment, but it persists throughout their careers. The percentage of newly licensed Canadian engineers who are female was only 17 percent in 2016 [12]. The number of women and girls interested in STEM fields is growing, showing that societal and educational changes are positively affecting the confidence of female students, but males continue to outnumber females as they progress in their education and in their careers $[5,8,14]$. This effect, often termed the "Leaky Pipeline," suggests that females are facing more obstacles than males in the same cultural and educational contexts $[7,8,20]$. The data demonstrates that tackling the issue of recruitment is not enough [2,9]. Addressing the issue of retention is just as important as recruitment, but there is little research, to the awareness of the authors, that discusses it beyond identifying that it exists. This warrants the need to begin identifying the root of this issue, and the direct causes. 
Undergraduate studies are the primary means of pursuing engineering careers, and are the first step students take in their professional journeys to become practising engineers. Unfortunately, many undergraduate engineering programs are built on a system that favors men and excludes women, and they continue to reinforce what has been termed a "Chilly Climate," comprised of a hypermasculine environment $[1,7,10,13,24]$. Embedded deep in the undergraduate engineering experience are male-dominated and sometimes intimidating discussions, subtle sexist humour, and a general assumption that females in the program are either rare and special or unqualified and should be ignored $[1,7,10,14]$. These factors draw attention to gender in what is supposed to be a gender-neutral and objective environment. Females are deterred from pursuing STEM fields like engineering when they are shown the stereotypical role models and environments connected with them, showing that the examples many undergraduate programs and peer and faculty behaviours look to are inherently anti-female $[7,13,24]$. These facets often single out females and further highlight the low number of females in engineering. Consequently, many female students' feelings of inclusion decline significantly throughout their journeys through their programs $[7,16,23]$.

Dismantling harmful biases against women that are present in engineering academic culture is an important step for building an educational environment that supports females. Self-confidence, belongingness, and self-efficacy have been shown to be related to females' plans to persist $[3,15,16,23]$. However, the components of the undergraduate engineering educational experience that are relevant to promoting feelings of belonging in females are unclear. Furthermore, while factors of self-perception have been shown to be uniquely responsible for recruitment rates, it is not known whether they are relevant to retention.

Therefore, the focus of the present study is the educational experiences of females in undergraduate engineering programs, to identify factors that contribute to the retention of women in engineering.

\section{METHODS}

The purpose of the research herein is to identify the challenges students encounter in their undergraduate engineering programs that may affect female students in ways different from male students. This is to understand the factors that may be causing issues in retention, and to eventually be able to remediate these causes. A 17question survey was distributed to undergraduate engineering students, and featured multiple choice and open-ended questions. These questions were selected based on issues identified in previous research.

\subsection{Participants}

A total of 261 invitees participated in the survey. Invitees included undergraduate engineering students at the institution in question; their emails were obtained through the institution's undergraduate engineering student society mailing list. Approximately $10.7 \%$ of invitees participated. All participants were undergraduate students in an accredited engineering program in Ontario. Of the 261 respondents, 138 identified as female, and 123 identified as male. The respondents stemmed from eleven different streams of engineering, and all years of study (14) were included. The ages of the participants ranged from 16 years old to 40 years old, with an average age of 20 years. All participants were invited to complete the survey via email invitation between November 2017 and January 2018. The email stated the purpose of the survey explicitly, and students of all genders and backgrounds were invited to participate. The survey obtained an ethics clearance through the Research Ethics Board at the university in consideration. Although not restricted within the clearance, the authors choose not to disclose the university in publication.

\subsection{Materials}

The survey was made available online through Qualtrics Experience Management, a data collection platform. Participants used a personal computer or other device connected to the internet to answer the questions. The survey was intended to be completed independently. The survey itself consisted of an informed consent form, given at the beginning of each survey, and 17 questions divided into four blocks according to theme. Questions were presented one block at a time (see Appendix A). All participants received the same questions in the same order. Where there were multiple possible answers in multiple choice questions, the order in which the answers were presented were randomized for each participant.

\subsection{Procedure}

First, participants logged onto a computer or device of their choice that had an established internet connection, and navigated to the survey link provided to them by the researchers (see Appendix B). Participants read through the informed consent form and, if they accepted the conditions of their participation, clicked the navigation button to begin the survey. If they declined to participate, they were free to close the browser. 18\% of students who opened the survey declined to participate.

The first block of questions in the survey dealt with demographics items such as engineering stream, age, gender, and year standing (see Appendix A for details). The next block asked questions related to student experiences. Depending on the question, participants either chose the answer(s) that best described their experience or typed in their response. Participants then 
optionally answered the question in the next block, which prompted them to share any further information they felt important and relevant to the survey. Finally, participants were given the option to leave their email or contact information should they have wished to participate in an in-person workshop discussing the survey and the subject matter (this workshop is beyond the scope of this current study and is future work planned by the authors). After completing the survey, participants' answers were submitted to the Qualtrics database and they were asked to close their browser.

\section{RESUltS}

Survey answers differed between genders and years of study. Chi square tests were used to determine whether significant relationships existed between participants' answers to demographic questions and survey questions related to educational experience. Results with $\mathrm{p}$ values less than 0.05 were considered to be statistically significant, as per common research standards [4].

Participants' answers about pursuing a voluntary fifth year after their degree changed depending on the year they were in. Only about $15 \%$ of first year students indicated that they intended to take a voluntary fifth year; this figure doubled to nearly $30 \%$ of fourth years who indicated that they intended to take a voluntary fifth year. Furthermore, there was a significant gender difference in fourth years' responses. By their fourth year, $46 \%$ of males indicated that they intended to pursue a voluntary fifth year. In contrast, only $16 \%$ of females said the same.

For the next question, professors from the university in consideration were asked to submit the names of a pair of engineers in their field of study: one man and one woman who were approximately comparable in terms of their level of recognition and in the contributions they have made to engineering. From this, 10 names (5 pairs of engineers) were selected, to represent a broad range of engineering disciplines. In the survey, the students were asked, "Of the following, choose the people that you recognize as having made contributions to the field of engineering" and were then presented with the names. They were free to select as many as they liked. Female names were selected a total of 197 times, while male names were selected a total of 237 times. Female participants chose female names approximately 1.1 times more often than male names. Male participants chose male names approximately 1.75 times more often than female names. Male participants were significantly more likely than female participants to show a preference for exemplars of one gender $\left(\chi^{2}(1, N=434)=10.94, \mathrm{p}<\right.$ 0.01).

Participants were asked how they most often interact with their professors, if they interact with them at all. In general, most students, regardless of year or gender, preferred to use email and after class periods to approach professors with questions. There were significant differences between students' responses depending on their year standing. First and second years, more often than third and fourth years, reported that they did not interact with their professors, and instead chose to ask Teaching Assistants (TAs) questions or rely on their peers. Third and fourth years, conversely, reported engaging with their professors directly and in-person more often than first and second years. This trend was significantly apparent for female students $\left(\chi^{2}(15, N=\right.$ 263) $=26.49, \mathrm{p}<0.05)$.

The survey examined whether students had ever felt intimidated or discouraged by their professors or peers. Results to this question can be seen in Figure 1. A further analysis was performed to determine if students reported more or less discouragement and intimidation as they proceeded through the years of their studies. In general, females reported being discouraged more often than men $\left(\chi^{2}(1, N=261)=11.07, \mathrm{p}<0.01\right)$. The difference between genders was particularly significant for students in second year $\left(\chi^{2}(1, N=66)=10.21, \mathrm{p}<0.01\right)$.

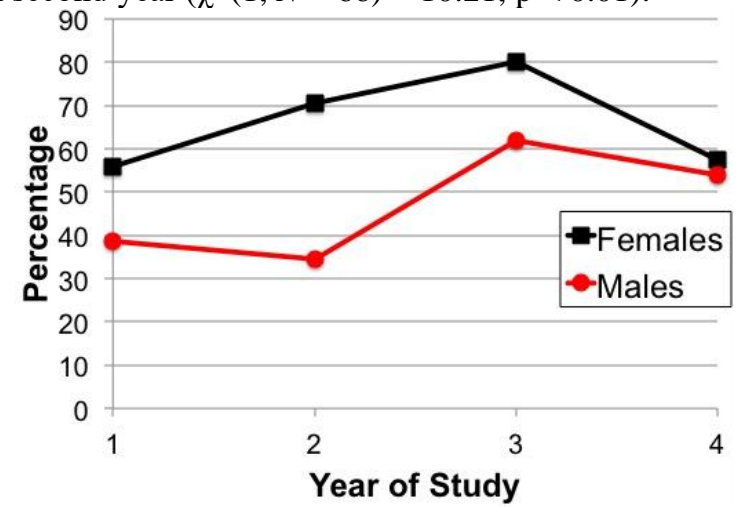

Figure 1. Percentage of respondents who responded "Yes" when asked, "Have you ever been discouraged or intimidated by your peers or professors?"

The final multiple choice question of the survey asked students how much opportunity for success they felt they had, relative to their peers. Overall, across all years of study, females felt they had a little $(33 \%)$ or much less (5\%) of a chance for success, compared to male respondents who felt they had much less of a chance for success just as often (5\%) as females but felt they had a little less of a chance less often $(22 \%)$ than females. Males mostly viewed their chances as equal (55\%) more often than females viewed their chances as equal (44\%). Females' responses were therefore skewed to less of a chance, while males' responses were skewed to equal chance (see Figure 2). 


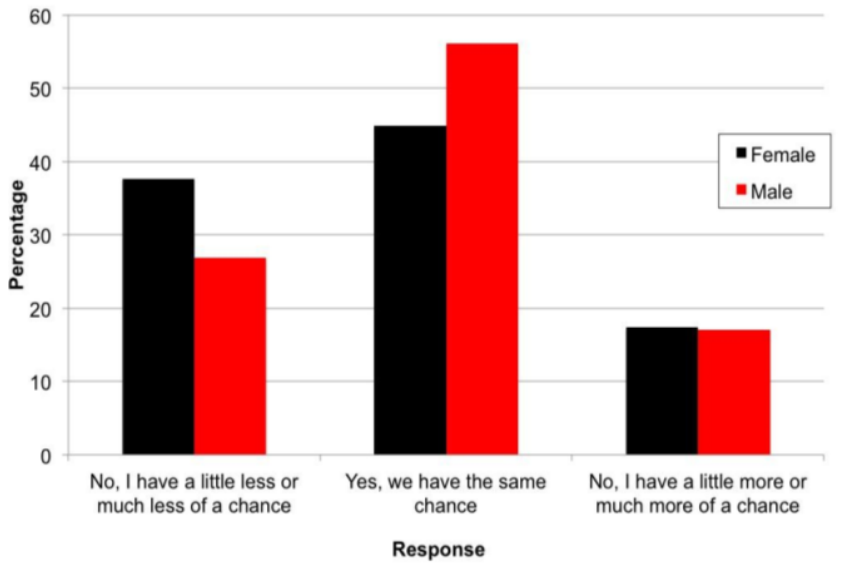

Figure 2. Responses from all years of study to the question, "Relative to your peers, do you feel that you have the same chance of securing opportunities in your program?"

Males across all years of study reported similar thoughts. Females in fourth year reported significantly different thoughts from first, second, and third years, instead believing that they had more equal opportunities for achieving success $\left(\chi^{2}(12, N=137)=21.52, \mathrm{p}<\right.$ $0.05)$.

There were no significant differences between males' and females' responses to the questions of whether they had a family member who is a practising engineer and whether they had someone that gave them career advice and support. Most students (58\%) indicated that they did not have a family member who is a practising engineer. In addition, about an equal proportion indicated that they had $(47 \%)$ and did not have $(53 \%)$ someone who provided them with career advice. There were also no significant differences between genders in participants' responses to the question, "What are your plans after graduation?." The majority of participants indicated that they intended to work in an engineering field.

There were no gender differences in response tendencies to the question of whether participants had difficulty finding group member when assigned group work. Most students answered "Sometimes" (35\%), "Rarely" (32\%), or "Never" (17\%), while few answered "Often" or "Always" (18\% collectively).

There were no significant gender differences in the responses made by students in different engineering programs.

\section{DISCUSSION}

Many of the results indicated that there are discrepancies between the experiences that male and female students are receiving throughout their engineering undergraduate studies.

\subsection{Student Background}

Looking at the questions that examined the background information of the participants, a slightly higher percentage of females $(44 \%)$ than males $(37 \%)$ reported having a family member who is a practicing engineer. While this question did not show statistical significance, it may suggest that, perhaps, female students are more likely to enter an engineering field if they have a role model already in the field, or if they have someone encouraging them to pursue engineering. Having a family member who is a practicing engineer may also help female students to be more informed of what engineering really is, and more aware of the opportunities that engineering holds [2,16]. It may indicate that a family member who is an engineer may help women to be more confident and supported, and may give them a muchneeded role model that can show them they belong in the field.

In general, the responses to the background questions showed that males and females had the same motivations and support when pursuing engineering. This is consistent with findings in literature $[10,19,22]$. The low recruitment rate of females to engineering programs, however, may indicate that in the general population, fewer females than males have the support from family members or mentors to pursue engineering education [10]. Further research would be needed to confirm this, and to see if a more statistically significant trend occurs in a larger sample size.

\subsection{Recognition of exemplars of different genders}

The question asking students to identify names they recognize as having made contributions to the engineering field may provide insight into the importance of representation. One possibility for the discrepancy between the frequency each name was selected by each gender is that, in general, the male names are more wellknown. This would explain why both genders had a high frequency of selecting these male names. Female students may be more inclined to seek out female role models, which could be one reason why they were more successful in selecting female names. Research has shown that although the gender of role models is not important for recruiting females into engineering, it is important for their retention $[8,9]$. Another possibility is that female and male exemplar engineers are in fact represented equally throughout engineering undergraduate studies, but certain names have more of a lasting impact on individuals. It was seen that both female and male students selected names that corresponded to individuals of their own gender more frequently than those of the opposite gender, but this effect was only significant for the male participants. This may be evidence that male students are 
more likely to recognize the achievements of other males in the field, over females in the field.

It is important for both male and female students to understand that all genders can be equally successful in the field of engineering. This can help to increase the amount of respect they have for one another. This could be accomplished through a number of ways, including by having a strong representation of female professors and lecturers, and providing students with examples and case studies that involve an approximately equal number of male and female engineers. Additionally, having female exemplars can help female students see that they can belong in the field, and may motivate them to persist in their studies and career $[9,19,24]$.

\subsection{Discouragement and intimidation}

Examining the opinions of the participants, it is apparent that female students are reporting higher levels of discouragement or intimidation in comparison to male students. It should be noted that, on average between all genders, $56 \%$ of respondents reported discouragement or intimidation by their peers or professors. This is a very high percentage, and may indicate a universal issue affecting a large proportion of undergraduate engineering students. Female students did report a higher incidence of discouragement or intimidation, with $65 \%$ of all female students indicating that they felt this way. Female students in all years of study reported a higher rate of discouragement or intimidation than male students, to some degree. This could possibly be due to discouraging or intimidating remarks having a greater or more lasting impact on female students, who recognize that they are often the minority in their classes. Belonging to a minority could make it appear as though negative remarks in general are more directed towards them and that they do not belong $[1,3,24]$.

Further research is required to identify the effect of this, and to understand what type of intimidation or discouragement is occurring within engineering undergraduate programs, and from whom. While this survey aimed at broadly identifying potential causes for low retention rates of female students, further research could begin to address if intimidation is occurring directly or verbally, and if so, whether it mostly occurs in a large classroom setting, or a more individualized setting such as office hours and private meetings. It could also be occurring non-verbally or indirectly, for example indirectly intimidating a student through not providing a comfortable office environment: having closed doors with blacked out windows or Do Not Disturb signs, doors with posters featuring jokes that may be interpreted negatively, and offices with an overwhelming display of achievements which may make students believe that their professors do not have the time for them. Intimidation or discouragement could also be occurring by calling students out in front of their peers for asking a question that indicates they may not be keeping up or completely understanding the course content. These theories are of course hypothetical, and examples of situations that could be further researched.

Expanding upon the topic of intimidation, it was seen that male students more frequently than female students indicated that meeting with their professors in-person was one of their typical modes of interaction. These meetings could occur either in the professor's office hours, or before and after class. This could possibly be a direct result of female students reporting higher levels of intimidation and discouragement, perhaps making them less comfortable approaching their professors directly. In terms of reaching out to their professor before or after class, intimidation may again play a role. If many students approach a professor to ask a question, and there is no pattern to the order students talk to the professor, more aggressive students may be more successful in having their questions answered. This scenario could cause more passive students to allow others to ask first, possibly running out of time for their own question to be answered, or they may be so discouraged that they abandon the question or topic altogether. The implications of this could be that the students who do not interact with their professors in person, or who interact less frequently, will have a less personal relationship with their professors. Knowing their professors can undoubtedly have a positive influence on students, and can be advantageous when the students need advice, resources, recommendations or reference letters. Professors can also help students by suggesting ideas of workplaces for them to pursue after graduation, or even by continuing to work with the students in graduate studies.

Particularly interesting in the results was that while female students sought the help of TAs more often than male students in their first two years, by third year they abandoned them in favour of approaching their professors. It was also notable that females experienced the highest level of intimidation in second year. These trends may be unrelated, but it is also possible that TAs are a significant source of discouragement for female students. If the latter case is true, then there may be significant implications for the level of respect TAs are trained to show to students and the accountability TAs have for their actions post-training. Closer monitoring of TA behaviour and track records may be useful in such cases. Alternatively, students could be seeking out their teaching assistants as a consequence of discouragement or intimidation from their professors, and perhaps they are more comfortable with their TAs. Professors, TAs, and peers have been identified numerous times in literature as potential sources of intimidation $[1,6,16]$, but the extent to which each of them have an impact on females' experiences on their own or in combination requires further research. 


\subsection{Self-confidence and opportunity}

The survey examined how students perceived their opportunities for success, in relation to their peers. When the students were asked if they felt they had the same chance of securing opportunities as their peers, $45 \%$ of female respondents indicated they felt they had the same chance, while $56 \%$ of male respondents felt this way. $38 \%$ of female respondents felt they had a little less or much less of a chance, compared to $27 \%$ of male respondents who selected this answer. $17 \%$ of both genders felt they had a little more or much more of a chance than their peers. In general, it appears as though a higher percentage of female students than male students felt as though they had less of a chance of securing opportunities. This could be due to a difference in levels of confidence.

If female students, or any students, see themselves a minority, this may lead to a lack of confidence or feelings of not belonging $[1,6,7]$. Consequently, they may believe that they are less likely to succeed in securing opportunities. The implications of this are that female students may be less likely to apply for opportunities if they believe that they are unlikely to succeed in obtaining them. Potential missed opportunities could include job opportunities, graduate school positions, and leadership roles. Additionally, an individual who believes they will be likely to succeed may come across as more confident. While networking or in a situation such as a job interview, this frame of mind may come across more strongly and have a more positive influence than an individual who is clearly not very confident, and who believes they are unlikely to secure the opportunity. The correlation between confidence and pursuit of opportunities was not directly examined in this survey, but literature has shown significant correlations between self-perception and women's decisions to pursue STEM $[3,15,23]$. Further research is needed to confirm the results of literature and address these speculations.

One factor that may help students believe they have a good chance for success is having diverse individuals in a variety of positions [7,21]. If an individual notices someone they identify with in a position they are interested in pursuing, their confidence may be increased $[5,7,8]$. Seeing someone successful in a position they wish to be in may encourage someone to believe they are also likely to succeed.

\subsection{Open ended questions}

Answers to the survey's open ended questions about what students considered to be their favourite and most frustrating parts of their program were generally consistent. Answers were categorized as either genderrelevant (i.e., mentioning gender explicitly impacting experiences) or gender-irrelevant (i.e., not mentioning gender in the experience report). Similar answers (i.e., those mentioning similar topics, such as friendship or community, academic facets such as course material or grading, etc.) were grouped together. Students most often cited challenging and interesting material, hands-on learning experiences, and close camaraderie as their favourite aspects of their program. The responses from males and females did not differ. As for frustrating parts of their program, an overwhelming number of students noted the quality of the TAs as gender-irrelevant aspects of experience. However, females often also mentioned gender-relevant notes like sexism from peers as a frustrating experience in their program about $10 \%$ of the time. Most of the examples they provided had to do with females' opinions being ignored in discussions and with the intimidating male to female ratios in some engineering programs. The fact that many of the female participants' responses to the question about the most frustrating part of their program concerned gender differences and sexism suggests that there is still much work to be done to improve the educational environment in undergraduate engineering. Furthermore, it is notable that males did not report gender-relevant frustrations at all.

The final question of the survey prompted participants to add any further comments on the topic of women in engineering (and in STEM in general) if they wished. Approximately $16.5 \%$ of participants responded to this question. The answers were varied. Some participants (both male and female) felt that they stood equal to their peers in their programs and were happy with the progress the institution and society at large are making with regards to the issue of women in engineering and STEM. Others, however, cited specific examples of being bullied and discriminated against for their gender during their time studying. These participants were all female, and there were no responses by men to this question that said the same. When females commented about their experiences, they were mostly negative $(81 \%)$. When males commented about gender-relevant experiences, they were never about themselves but about their female peers. About half the time, males positively acknowledged their female peers, and the other half of the time, they pointed out that their female peers can face unique obstacles because of their gender. There were a couple of comments made by males that were sexist against their female peers; females never made such comments against other females or against males. These comments show that sexism even persists in the undergraduate engineering environment.

Comments from the open ended questions further went on to provide insight as to how students are interpreting the causes of the differences in enrolment and retention between genders in the engineering programs. Some participants indicated that they believed that differences in the enrolment were purely out of choice, that females 
were less represented in engineering because they simply chose to enter it less frequently than males, and voluntarily choose to leave the profession more frequently than males. This may signify that there is some confusion over why enrolment and retention rates of females in the engineering field are an issue, and that the societal influences affecting students may not be well understood, along with the challenges that female students uniquely face in their undergraduate degrees. It is apparent that better education about the issue of women in engineering (and STEM more broadly) and on peer respect are needed.

\subsection{Non-significant results}

Participants gave numerous negative comments about their peers in their responses to open ended questions. Nonetheless, the difference between genders' responses to the question about finding group members for group work was non-significant. A possible explanation for this may be that peer interactions alone do not significantly impact students' perceptions of belonging or intimidation. Other components in the university system (including professors, TAs, etc.) may also play a part, and their impacts only become significant when added together. However, some literature has identified that the gender composition of groups can significantly impact group success and elevate the group members' chances of securing opportunities; male-dominated groups have especially been shown to carry the most organizational power and influence, and women are routinely excluded from these $[6,8,10,14]$. More research is needed on this topic to fully understand it and our results.

Despite many of the participants' comments pointing out gender discrimination differences depending on program, coupled with literature identifying different patterns of discrimination depending on engineering subdiscipline [1,2,7], there were no significant gender differences in participant experiences between programs. One reason for this may be due to the unbalanced distribution of participants between the different engineering programs (mechanical, electrical, etc.). Some programs had very few representatives that took the survey, while others had many. For the groups that had very few representatives, results may have been unfairly biased. Consequently, there were not enough participants from each respective engineering stream to properly compare some of the streams. This is a limitation of the study. Future research investigating the differences in experiences between males and females in programs with higher or lower ratios of men to women would be beneficial.

\subsection{Study Limitations}

A limitation of this study is that the impact of racial, sociocultural, or economic factors on students' experiences in their programs were not directly examined. These may partially explain the high percentage of students that, regardless of gender, felt discouraged or intimidated in their program. Students who are minorities in one or more factors, potentially in combination with being part of a gender minority, may be more susceptible to developing perceptions of not belonging [21]. Consequently, answers to some of the questions regarding discrimination and opportunity may have been distorted. Further investigation about the interrelationships between different sociocultural factors would shed some light on the subtleties that may be present in the details.

A further limitation of the study is that not all engineering disciplines were equally represented. It is unclear how different engineering disciplines may tackle the issue of women in engineering. Different programs and institutions have been shown to impact female persistence in the field in different ways $[2,5,7,10,15,18]$.

It was assumed that participants taking the survey would complete it independently. The possibility that students may collaborate was not controlled for. When participants work in groups they may hesitate to draw attention to aspects of their identities or experiences that mark them as being more or less privileged compared to their peers. For fear of being judged by those who can read their answers, participants may answer in a way that fits with the trend of their group. It did not seem as though participants worked in groups for this survey, based on the times and locations in which the surveys were completed and analysis of similar answers. Nevertheless, future iterations of survey-type research may benefit from clearer instructions to complete the survey alone.

Finally, it is likely that of all students invited, those who participated were those who had greater initiative and time. An important demographic may have been missed in the survey because they were busy, uninterested, or otherwise unavailable at the time of recruitment. For example, students who are raising families, working extensively in addition to studying, or returning to school at a later point in life may have been missed. To remedy this, it would be prudent to implement a longer data collection period and clear incentives to motivate students to participate. It is important to engage a diverse demographic to better understand whether the trends seen are universal or sensitive to demographic. 


\section{Conclusions}

Though it has been shown that female and male students hold the same potential for success academically, it is clear from the results that females are having different experiences in their undergraduate engineering programs than males. It is important to understand these experiences, in order to improve the retention rates of female engineering students, from enrolment all the way through until they achieve Professional Engineer status.

In examining the survey results, females reported being discouraged or intimidated by peers and professors more often than males. The survey results also showed that both genders identify exemplar engineers of their own gender more frequently than the exemplar engineers of the opposite gender; however this trend is notably more pronounced in the answers of the male participants. This may indicate the need to better educate students on the accomplishments of successful engineers, in order to encourage the perception that any individual has an equal opportunity to be successful in the profession, and to ensure that the contributions of all genders of engineers are recognized.

Although there were many comments from both males and females that showed that they felt equal to their peers regardless of gender, when given the chance to voice any additional thoughts they may have, female students also cited numerous gender-specific problems and situations that they encounter in their everyday academic environment. Additionally, there were many comments that reinforced the notion that the educational environment in undergraduate engineering leaves women less motivated to further pursue a career in the field. This demonstrates that although there have been advancements and initiatives working towards amending the issue of retention, further research is required to better understand what is causing female engineering students to leave the profession.

The need to change the atmosphere prevalent in undergraduate engineering to better support female, and all students, and encourage respect (and actively discourage disrespect) between students is apparent.

Further research on this topic could include expanding this survey to other institutions across the country, adding questions that control for other sociocultural aspects of identity, and examining the subtle details embedded in each question, to better understand whether the factors that were found to be significant are causally related to low retention rates of women in engineering. Lastly, the study could be expanded to include early career practitioners (post-graduation) and students at the graduate level.

\section{References}

[1] S.J. Aiston, "Whose Academy? Gender and higher education," in Researching Higher Education: International Perspectives on Theory, Policy and Practice, J.M. Case and J. Huisman, Eds. New York, NY: Routledge, 2015, pp. 80-96.

[2] Golnaz Arastoopour, Naomi C. Chesler, and David W. Shaffer, "Epistemic Persistence: A Simulation-based Approach to Increasing Participation of Women in Engineering," Journal of Women and Minorities in Science and Engineering, vol. 20, no. 3, pp. 211-234, 2014.

[3] London Bonita, Lisa Rosenthal, Sheri R. Levy, and Marci Lobel, "The influences of perceived identity compatibility and social support on women in nontraditional fields during the college transition," Basic and Applied Social Psychology, vol. 33, no. 4, pp. 304-321, 2011.

[4] I.D.J. Bross, "Critical levels, statistical language and scientific inference," in Foundations of statistical inference, V.P. Godambe and D.A. Sprott, Eds. Toronto, ON: Rinehart \& Winston of Canada Ltd., 1971, pp. 500-513.

[5]: Ronald J. Burke and Mary C. Mattis, Women and Minorities in Science, Technology, Engineering and Mathematics: Upping the Numbers. Massachusetts, USA: Edward Elgar Publishing Inc., 2007, 379 pp.

[6] Nilanjana Dasgupta, Melissa M. Scircle, and Matthew Hunsinger, "Female peers in small work groups enhance women's motivation, verbal participation, and career aspirations in engineering," in Proceedings of the National Academy of Sciences, Susan T. Fiske (Ed.) (21 April 2015), vol. 112, no. 16, 4988-4993.

[7] Emmeline de Pillis and Lisette de Pillis, "Are engineering schools masculine and authoritarian? The mission statements say yes," Journal of Diversity in Higher Education, vol. 1, no. 1, pp. 33-44, 2008.

[8] Tara C. Dennehy and Nilanjana Dasgupta, "Female peer mentors early in college increase women's positive academic experiences and retention in engineering," in Proceedings of the National Academy of Sciences, Sapna Cheryan (Ed.) (6 June 2017), vol. 114, no. 23, pp. 59645969.

[9] Benjamin J. Drury, John O. Siy, and Sapna Cheryan, "When Do Female Role Models Benefit Women? The Importance of Differentiating Recruitment from Retention in STEM," Psychological Inquiry, vol. 22, pp. 265-69, 2011.

[10] Xiang-Yun Du, "Gendered practices of constructing an engineering identity in a problem-based learning environment," European Journal of Engineering Education, vol. 31, no. 1, pp. 35-42, 2011.

[11] Engineers Canada, 2016 Engineering Enrolment and Degrees Awarded Report. 2017, 84 pp. Available from https://engineerscanada.ca/reports/enrolment-and-degreesawarded-report.

[12] Engineers Canada, Percentages of newly licensed engineers who are women [Graph], 2017. Available from https://engineerscanada.ca/diversity/women-in-

engineering/30-by-30.

[13] Wendy Faulkner, "Nuts and Bolts and People: GenderTroubled Engineering Identities," Social Studies of Science, vol. 37, no. 3, 2007. 
[14] Wendy Faulkner, "Doing gender in engineering workplace cultures. I. Observations from the field," Engineering Studies, vol. 1, no. 1, pp. 3-18, 2009.

[15] Allison Godwin, Geoff Potvin, Zahra Hazari, and Robynne Lock, "Identity, Critical Agency, and Engineering: An Affective Model for Predicting Engineering as a Career Choice," Journal of Engineering Education, vol. 105, no. 2, 2016.

[16] Irene F. Goodman et al., A Comprehensive Evaluation of Women in Engineering Programs. Cambridge, MA: Goodman Research Group Inc., 2002, 264 pp.

[17] Allison Gonsalves, "Diversifying the STEM Community of Tomorrow: Educational, Extracurricular, and Community Influences," NSERC Gender Summit 11 (Montreal, ON; 6-8 November), 2017.

[18] Amanda L. Griffith, "Persistence of women and minorities in STEM field majors: Is it the school that matters?," Economics of Education Review, vol. 29, no. 6, pp. 911-922, 2010.

[19] Darcy W. Hango, "Gender differences in science, technology, engineering, mathematics, and computer science (STEM) programs at university." Science, vol. 6, no. 6.6, pp. 5-8, 2013.

[20] Catherine Hill, Christianne Corbett, and Andresse St Rose, Why so few? Women in science, technology, engineering, and mathematics, Washington, DC: American Association of University Women, 2010.

[21] Alexis Krivkovich, Kelsey Robinson, Irina Starikova, Rachel Valentino, and Lareina Yee, Women in the Workplace 2017, McKinsey \& Company, 2017. Available from https://www.mckinsey.com/global-themes/genderequality/women-in-the-workplace-2017.

[22] Adam V. Maltese and Robert H. Tai, "Pipeline persistence: Examining the association of educational experiences with earned degrees in STEM among U.S. students," Science Education Policy, vol. 95, no. 5, pp. 977-907, 2011.

[23] Rose M. Marra, Kelly A. Rodgers, Demei Shen, and Barbara Bogue, "Women Engineering Students and SelfEfficacy: A Multi-Year, Multi-Institution Study of Women Engineering Student Self-Efficacy," Journal of Engineering Education, vol. 98, no. 1, pp. 27-38, 2009.

[24] Alison Phipps, "Engineering Women: The 'Gendering' of Professional Identities," International Journal of Engineering Education, vol. 18, no. 4, pp. 409414, 2002.

[25] Erika D. Tate and Marcia C. Linn, "How Does Identity Shape the Experiences of Women of Color Engineering Students?," Journal of Science Education and Technology, vol. 14, no. 5-6, pp. 483-493, 2005.

\section{APPENDiX A: SURVEY QUESTIONS}

\section{BLOCK 1}

Q1 Which stream of engineering are you in?

oAerospace

oArchitectural Conservation and Sustainability

oBiomedical and Electrical

oBiomedical and Mechanical
oBiosystems

oCivil

oCommunications

oComputer Systems

oElectrical

oEngineering Physics

oEnvironmental

oGeological

oIndustrial or Manufacturing

oMaterials or Metallurgical

oMechanical

oMining or Mineral

oSoftware

oSustainable and Renewable Energy

oOther

Q2 What is your year standing?

o1 o2 o3 o4

Q3 Are you taking a voluntary 5th year in addition to your core degree program? (Note: This does not include students who take co-op and are in their 5th year of studies but have 4th year standing.)

oYes oNo

Q4 What is your gender?

oMale oFemale oOther / Prefer not to say

Q5 How old are you?

\section{BLOCK 2}

Q6 Do you have a family member who is a practising engineer?

oYes oNo

Q7 Do you have someone who provides you with career advice?

oYes oNo

Q8 Of the following, choose the people that you recognize as having made contributions to the field of engineering.

$\square$ Catherine Karakatsanis $\square$ Leah Mackinnon

$\square$ Julie Payette $\square$ Ada Lovelace $\square$ Hedy Lemarr

$\square$ Sean Frisky $\square$ Chris Hadfield $\square$ Charles Babbage

$\square$ John Randall $\square$ Bill Baker

*Note: the appearance of answers to question 8 was randomized for each participant

Q9 How do you typically interact with your professors?

oE-mail and/or online

oMeeting them in office hours

oTalking to them before/after class

oThrough someone else (e.g., asking a friend to talk to the professor)

oI don't interact with my professors, but talk to Teaching Assistants (TAs) instead.

oI don't interact with my professors or my TAs.

Q10 Have you ever been discouraged or intimidated by peers or professors in your program?

oYes oNo 
Q11 Relative to your peers, do you feel that you have the same chance of securing opportunities in your program?

oNo, I have much less of a chance

oNo, I have a little less of a chance

oYes, we have the same chance

oNo, I have a little more of a chance

oNo, I have much more of a chance

Q12 Have you ever had difficulty finding group members when assigned group work?

oNever oRarely oSometimes oOften oAlways

Q13 What are your plans after graduation?

oWorking in an engineering field

oWorking in another field (non-engineering)

oPursuing further studies in an engineering field

oPursuing further studies in another field (non-

engineering)

oTaking time off

oOther

Q14 What is the most frustrating part of your program?

Q15 What is your favourite part of your program?

\section{BLOCK 3}

Q16 If you have any further comments about your educational experience that you wish to share, enter them below. Otherwise, click the Next button.

\section{BLOCK 4}

Q17 If you would like to participate in an in-person workshop and discussion regarding women in engineering, please leave your e-mail address/contact information below.

Please note that if you do this, your responses will no longer be anonymous. However, you will not be personally identified in any publication. If you do not wish to participate, click Next to finish the survey.

\section{APPENDIX B: RECRUITMENT EMAIL}

Hi there,

We are [researcher names and affiliations]. We are working on a research project concerning the experiences of women in undergraduate engineering programs, under the supervision of [supervising professor].

We would like to invite you to participate in a short survey on your educational experiences as a student of engineering. Undergraduate students of any gender are invited to participate. This study aims to find out whether there are differences in student experiences at the undergraduate level depending on gender. The recruitment rate of women in engineering has been stagnant for years, and the balance between genders in the field has consistently favored men (Engineers Canada, 2016). The purpose of our research is to examine whether there are aspects of the university experience that may be contributing to the problem.

This study involves one short survey that will be available online. If you would like to participate, please follow this link: [Qualtrics survey link].

This project does not involve any professional and emotional risks, and care will be taken to protect your identity. This will be done by keeping all responses anonymous. Research data will only be accessible by the researcher and the research supervisor.

You will have the right to end your participation in the study at any time, for any reason. If you choose to withdraw, all the information you have provided up to that point will be destroyed. There is no special compensation associated with this study.

This ethics protocol for this project was reviewed by the [Institution] Research Ethics Board, which provided clearance to carry out the research (Clearance \#).

Thank you.

Sincerely,

[Researcher names] 